seas demand are set forth with impressive clarity, and in which the tribute paid to the British contribution in the past is matched by insistence on the opportunity and the responsibility which rest on Britain in the future. The Committee is convinced that the present response of Britain is still inadequate and does not match the urgency of the situation or the determination of the Governments of developing countries to achieve quicker and better results. Britain is, for example, failing in some degree to use her outstanding experience in the training field, and there is a grave danger that the great experience of the past will become dated and irrelevant if it is not quickly refreshed by greater study of the new situations overseas and by closer personal contact with them. The effort demanded of Britain by the recommendations of this Report is considerable in terms of finance and manpower, and will sometimes fall where shortages are most acute, for example, in the universities. Nevertheless, the demand is one that should be met promptly and generously from the point of view of the developing countries alone. No careful reader of the Report can be in any doubt that the benefits will be unbiased and that the action recommended by the Bridges Committee will greatly benefit the universities and other institutions in Britain as well as the standards and practice of public administration in face of demands into which scientific and technological factors increasingly enter.

\section{CELL WALL ARCHITECTURE}

\section{The Plant Cell Wall}

A Topical Study of Architecture, Dynamics, Comparative Chemistry and Technology in a Biological System (International Series of Monographs on Pure and Applied Biology Plant Physiology Division.) By S. M. Siegel. Pp. xix +123 . (Oxford, London, New York and Paris : Pergamon Press, 1962.) $42 s$.

T is now more than four years since the major works of Frey-Wyssling and of Roelofsen appeared, and however good a book may be-and these two were excellentit is their inexorable fate to become in some respects outdated. So it is with these. The newer findings have been recorded in a number of review articles; but the appearance of a new text should be timely and welcome. It was therefore with the keenest anticipation that I opened this new book by an author whose name promises both a new approach to the older problems and authoritative statements on the newer. I can only regret that, even after making due allowance for the author's unenviable task in following two such distinguished predecessors, the outcome is disappointing. A text on The Plant Cell Wall (without qualification) in 107 pages surely needs careful choice of material, meticulous accuracy of statement and copious illustrative (and text-saving) diagrams. In none of these does the present book approach a standard which can be accepted even by the most generous reviewer.

The introduction (of slightly more than six pages) dealing with the morphology of "Walls and Cells" is so sketchy as to be completely misleading. An author, moreover, who says (p. xvi) that "The anatomically defined fibre is not to be mistaken for seed hairs (cotton) ..." should not then (pp. 34 and 91) refer to cotton hairs as fibres. Chapter I opens with a résumé of analytical principles and procedures the brevity of which would be commendable were it not so compounded of loose statements as to be virtually useless. To quote only one example (p. 8), " . . . system of isotropic rods or planes as a whole will rotate plane polarized light ..." (the italics are mine). The ensuing descriptions of the results of analyses are no tighter, for example (p. 15), "the crystallographic unit cell" [of cellulose] "is rhombohedral" followed by the correct monoclinic cell; "the $10.3 \AA$ identity period corresponds to the distance between number one carbon of one residue and the oxygen at the number four carbon of the second residue" (and this without referring to the corresponding figure which does not appear until p. 36, in a part of the book where there are two Fig. 1's, two Fig. 2's and two plates also labelled Fig. I and Fig. 2 with no qualification). Incidentally, Fig. 1 on p. 35 is credited to Wardrop and Bland whereas it is in fact due to Frey-Wyssling. After discussing the whole of wall structure in twenty-nine pages, the author then turns to cell-wall dynamics (2l pages). This leads off with observations on biosynthesis which are again too generalized and too loosely expressed to enable the reader to distinguish established fact from speculation. The subsequent treatment of wall expansion is scarcely clarified by such statements as (p. 53) " . . . transversely oriented [optically negative] fibrils" since the fibrils themselves are optically positive and the sign of birefringence here is in any case subject to a definition [not given] different from that of optical crystallographers. Chapter 3 , under the strange title "Comparative Chemistry of Intercellular Substances and Walls", contains some of the oddest statements of the whole book. On p. 84, for example, we find " . . the phaeophycean polyuronide is calcium alginate, poly-1,4- $\alpha$-D-galacturonic acid, an isomer of pectic acid", afterwards corrected to (p. 94) "Natura] alginic acid is poly-1,4-anhydro- $\beta$-D-mannuronic acid . . ." but still not taking up the fact that. alginic acid is now known to contain large amounts of poly-1,4- $\beta$-L-guluronic acid. The final chapter deals with properties and uses of cell walls and is again far too sketchy to have any real value.

The author has taken his work far too widely to be treated in a mere 107 pages, and it would clearly have been better to have omitted, for example, any discussion of crystalline deposits in cell walls and perhaps the whole of Chapter 4 and to have expanded the rest. The text is spattered throughout with printing errors (I myself counted 40 even when not proof-reading) and numerical mistakes (for example, p. 100, where $100 \mathrm{kgm}$. dry wood is said to produce $400 \mathrm{kgm}$. fermentable sugar). No references are quoted in the text, and the reading list, while directing the reader to papers on, for example, enzymes in apples and the biochemistry of insect cuticles, makes no mention of the 1959 books by Roelofsen and by Frey-Wyssling or of the numerous relevant articles in the Encyclopedia of Plant Physiology. There are indeed no references specifically to cell wall studies after 1959. The reference list is, besides, no more free of inaccuracies than is the rest of the book. $\quad$ R. D. Preston

\section{GENETICAL STATISTICS}

The Statistical Processes of Evolutionary Theory By Prof. P. A. P. Moran. Pp. vii +200. (Oxford: Clarendon Press; London: Oxford University Press, 1962.) 38s. net.

T $T$ is no easy task either to write or to read a systematic and rigorous account of the mathematical aspects of the genetics of natural populations. But Prof. Moran has bravely attempted the former, and in so doing he has cleared a path for the reader who really wishes to understand the subject. However, it must be understood that this book will be of interest to mathematicians who have a smattering of genetics and not to geneticists who have a smattering of mathematies.

The author ably surveys some of the theoretical works of Fisher, Haldane and Wright, and of those, including himself, who have begun their contributions to the field 